\title{
A multicriteria lifespan energy efficiency approach to intelligent building assessment
}

Article

Accepted Version

Chen, Z., Clements-Croome, D., Hong, J., Li, H. and Xu, Q. (2006) A multicriteria lifespan energy efficiency approach to intelligent building assessment. Energy and Buildings, 38 (5). pp. 393-409. ISSN 0378-7788 doi:

https://doi.org/10.1016/j.enbuild.2005.08.001 Available at https://centaur.reading.ac.uk/11841/

It is advisable to refer to the publisher's version if you intend to cite from the work. See Guidance on citing.

To link to this article DOI: http://dx.doi.org/10.1016/j.enbuild.2005.08.001

Publisher: Elsevier

All outputs in CentAUR are protected by Intellectual Property Rights law, including copyright law. Copyright and IPR is retained by the creators or other copyright holders. Terms and conditions for use of this material are defined in the End User Agreement.

www.reading.ac.uk/centaur 
Central Archive at the University of Reading

Reading's research outputs online 


\title{
A multicriteria lifespan energy efficiency approach to intelligent building assessment
}

\author{
Zhen Chen ${ }^{\text {a,* }}$, Derek Clements-Croome ${ }^{\text {a }}$, Ju Hong \\ b, Heng $\mathrm{Li}^{\mathrm{b}}$, Qian $\mathrm{Xu}^{\mathrm{b}}$ \\ a School of Construction Management and Engineering, The University of \\ Reading, Reading, UK \\ ${ }^{\mathrm{b}}$ Department of Building and Real Estate, The Hong Kong Polytechnic \\ University, Hong Kong, China
}

Received 15 July 2005; received in revised form 29 July 2005; accepted 5 August 2005

* Corresponding author. Tel.: +44 7979830 187. E-mail address: z.chen@ reading.ac.uk (Z. Chen)

\begin{abstract}
This paper presents a multicriteria decision-making model for lifespan energy efficiency assessment of intelligent buildings (IBs). The decision- making model called IBAssessor is developed using an analytic network process (ANP) method and a set of lifespan performance indicators for IBs selected by a new quantitative approach called energy-time consumption index (ETI). In order to improve the quality of decisionmaking, the authors of this paper make use of previous research achievements including a lifespan sustainable business model, the Asian IB Index, and a number of relevant publications. Practitioners can use the IBAssessor ANP model at different stages of an IB lifespan for either engineering or business oriented assessments. Finally, this paper presents an experimental case study to demonstrate how to use IBAssessor ANP model to solve real-world design tasks.
\end{abstract}

Keywords: Intelligent building; Life cycle assessment; Analytic Network process; Energy efficiency

\section{Introduction}

Sustainable building design, construction and operation require innovations in both engineering and management areas at all stages of a building's life. The lifespan of buildings is composed of a series of interlocking processes, starting from initial architectural and structural design, through to actual construction, and then to maintenance and control as well as to eventual demolition or renovation of buildings. Inside this lifespan, essential requirements are generated from considerations of social, environmental, and economic issues for high- efficient energy-saving building systems in compliance with building codes and regulations. In this regard, building assessment is becoming popular in order to have a standard method to evaluate new and existing building design. For example, the U.S. Green Building Council [89] developed the Leadership in Energy and Environmental Design 
(LEED) Green Building Rating System asa voluntary, consensus-based national standard for developing high-performance, sustainable buildings. The Japan Sustainable Building Consortium [99] developed the comprehensive assessment system for building environmental efficiency (CASBEE) system as a new environmental assessment system to meet both the political requirements and market needs for achiving a sustainable society. The Building Research Establishment Ltd. [9] from UK developed the Building Research Establishment Environ- mental Assessment Method (BREEAM) to assess the environmental performance of both new and existing build-ings. Meanwhile, intelligent buildings (IBs) are also under assessment according to their IB related characteristics and actual circumstances. For example, the Asian Institute of Intelligent Buildings (AIIB) [5, 22] from Hong Kong devel- oped an IB Index system to specifically assess the performance of IBs; and the BRE developed a matrix tool called MATOOL for assessing the performance of intelligent buildings [12]. Although a new international benchmark of IB assessment is under developing by the Continental Automated Building Association [18] in Canada, there is not a standard sustainable IB assessment tool, and this leads to the research being presented in this paper.

Based on current practice in building assessment, the authors of this paper present a multicriteria decision-making model using the analytic network process (ANP) [70-72] to evaluate the lifespan energy efficiency of IBs. To undertake this task, this paper firstly reviews building assessment systems currently adopted in Australia, Canada, Hong Kong, Japan, Korea, mainland China, The Netherlands, the United Kingdom and the United States. A quantitative indicator selection approach to energy-time consumption during building lifespan is proposed based on a Strategic Intelligent Building Evaluation and Renovation (SIBER) model, which is a development of the Through Life Environment Business Model developed by the University of Reading for lifecycle assessment [24]. Under the SIBER model, the authors further developed a Tactical Intelligent Building Evaluation and Renovation (TIBER) model, and from which an ANP model named IBAssessor is then structured based on a group of key performance indicators (KPIs) [2], which are selected through a proposed quantitative approach called energy-time consumption index (ETI). In order to further exam the effectiveness of IBAssessor, an experimental case study is finally conducted with detailed calculation and evaluation procedures. The paper concludes that auditors can use the IBAssessor when it is necessary to evaluate the lifespan energy efficiency of IBs and therefore select the most appropriate building.

The significant contributions of this paper include an energy-time analysis based quantitative approach to KPI selection, a set of criteria applied to IB assessment regarding their lifespan performances of energy efficiencies, and an ANP model for lifespan energy efficiency assessment in IB design, construction and operation. Meanwhile, the evidence to be presented in this paper include the SIBER model for building lifespan performance management; the TIBER model for IB assessment; the energy-time analysis based quantitative approach to KPI selection; the ANP model for selecting the most appropriate IB alternative based on lifespan energy-time consumption analysis; and an experi-mental case study. It is the authors' expectation that practitioners including managers and auditors can use the proposed IBAssessor for energy efficiency assessment in IB design, construction and operation. 


\section{Assessment methods}

According to the latest literature [24], an IB is one that provides a productive and costeffective environment through optimizations based on its three basic elements-people (owners; occupants; visitors, etc.); products (materials; fabric; structure; facilities; equipments; services); and processes (automation; control; systems; maintenance; performance evaluation) - and the interrelationships between them. IBs use integrated and intelligent systems to provide a rewarding experience for the building owners, property managers, occupants and visitors to achieve their goals. These goals include the lifespan high energy efficiency, the environmental- friendly built environment with substantial safety, security, well-being and convenience, a lower life-cycle cost, and long- term flexibility and marketability, which lead to achieve a high- level of buildings that have the highest social, environmental and economic values. Meanwhile, IBs use advanced information and communication technologies to develop embedded data collection and information networks through which its services systems are automatically controlled to respond using an approach similar to the sensor system of human beings, guided by predictions based upon knowledge of the past situations of the building and usage, maintained in an integrated data base. Thus, IBs should be sustainable, healthy and technologically aware, meet the needs of occupants and business, and should be flexible and adaptable to deal with change.

Practitioners use assessment methods to evaluate the design or the performance of IBs. There are three main kinds of assessment methods including building rating, computer simulation and facilities management [24]. The rating method relies on a series of factors/indicators related to the design and the performance issues together with their defined scales to rate an IB. The simulation method uses artificially settings based on realworld data from the operation of IBs. The facilities management method use experts' knowledge to achieve goals in practical IB design, construction and operation. The applications of the first two kinds of assessment methods can be at either design or operation stage of any IB under evaluation, while the third method can be applied at all stages of the IB life cycle.

The authors are conducting an extensive literature review on conventional building assessment systems in order to extract a group of indicators for the proposed ANP model. Current building assessment systems under review include:

- Assessment Standards for Certifying Intelligent Buildings (ASCIB, by Intelligent Building Society of Korea (IBSK), Seoul, Korea) [39],

- Building Quality Assessment (BQA, by Building Economics Bureau, UK),

- Building Research Establishment Environmental Assessment Method (BREEAM, by Building Research Establishment Ltd. (BRE), UK) [9],

- Building Sustainability Assessment Tool (BSAT, by the Department of Trade and Industry, UK) [73],

- Building IQ Rating Criteria (BIQRC, by Task Force 1- Intelligent Building Ranking System, Continental Automated Building Association (CABA), Ottawa, Canada) [18],

- Comprehensive Assessment System for Building Environ- mental Efficiency 
(CASBEE, by Japan Sustainable Building Consortium (JSBC), Japan) [99],

- Design Quality Indicator (DQI, by Construction Industry Council, UK),

- Environmental Performance Express of Buildings (Eco- Quantum, by IVAM, The Netherlands),

- Assessment Framework and Green Building Tool (GBTool, by the International Initiative for a Sustainable Built Environment (IISBE), Canada) [100],

- Green Mark for Buildings (GMB, by Building and Construction Authority, Singapore) [104],

- Hong Kong Building Environmental Assessment Method (HK-BEAM, by HKBEAM Society, Hong Kong) [101],

- IB Index (by Asian Institute of Intelligent Buildings (AIIB), Hong Kong) [5,22],

- IB Rating (by Shanghai Construction Council (SCC), Shanghai, China) [74],

- Leadership in Energy and Environmental Design/Green Building Rating System (LEED, by U.S. Green Building Council, USA) [89],

- A matrix tool for assessing the performance of intelligent buildings (MATOOL, by Building Research Establishment Ltd. (BRE), UK) [12],

- National Australian Built Environment Rating System (NABERS, by Department of the Environment and Heritage, Australia) [102],

- Office Scorer (Sustainable Refurbishment/Redevelopment Decision Support Tool for office buildings, Building Research Establishment Ltd. (BRE), UK) [8],

- Sustainable Project Appraisal Routine (SPeAR, by Arup, UK) [103], and

- Sustainability Checklist (Assessment of the social, environ- mental and economic impact of a proposed development, by the South East England Development Agency (SEEDA), UK) [7].

According to the literature review focusing on the building assessment systems, the authors noticed that there are several successful applications of rating methods for building performance assessment. For example, the LEED Green Building Rating System ${ }^{1}$ is a voluntary, consensus-based national standard for developing high-performance, sustainable buildings in the United States [89]. The Environmental Assessment Method by the Building Research Establishment Ltd. (BREEAM) is adaptable to assess the environmental performances of both new and existing buildings in the UK [9, 30]. The Standard Assessment Procedure (SAP) of the National Home Energy Rating (NHER) is the UK's premier energy labelling scheme recommends by the UK Government for home energy rating [58]. On the other hand, although simulation methods can provide more reliable results than rating methods using various conditions in the building lifespan based on objective and subjective settings in computer programmes; there is not a comprehensive simulation tool for practitioners to conduct IB assessment at present. On the contrary, popular simulation approaches mainly focus on only one part of building performance such as thermal environment or acoustic environment, and it is a difficult task to develop a tool for complete performance simulations of the total environment in buildings. In this regard, rating systems have been widely adopted in building performance assessments, and the simulation method is often adopted in building design.

Among these building assessment systems, there have been several rating methods designed for for IB assessment, and there are some new rating systems under development 
as well. Table 1 gives a summary of representative methods based on current practice in IB assessment. According to the literature review, the authors identified six assessment clusters of indicators centreing on Architecture, Engineering, Environment, Economics, Management, or Sociology. Among the five IB assessment systems listed in Table 1, the AIIB method, i.e. IB Index method [5, 22] is the most comprehensive one that covers all of the seven assessment clusters, and the SCC method [74] is mostly focused on the one assessment cluster, i.e. Engineering. The CABA method [18] aims to benchmark the IB assessment in a more general way but is still under construction. And the BRE method, i.e. MATOOL [12] and the IBSK method [39] have less coverage of assessment clusters than the IB Index. Therefore, the AIIB method is currently the most comprehensive method for IB assessment.

Table 1

The main categories of criteria adopted in rating methods for IB assessment

\begin{tabular}{|c|c|c|c|c|c|c|}
\hline \multirow{2}{*}{$\begin{array}{l}\text { Assessment } \\
\text { ciusters }\end{array}$} & \multicolumn{6}{|c|}{ Main modules by each assessment system } \\
\hline & $\begin{array}{l}\text { AIIB method } \\
{[5,22] \text { (Hong }}\end{array}$ & $\begin{array}{l}\text { BRE method } \\
{[12](\mathrm{UK})}\end{array}$ & $\begin{array}{l}\text { CABA } \\
\text { method [18] }\end{array}$ & $\begin{array}{l}\text { IBSK method } \\
\text { [39] (Korea) }\end{array}$ & $\begin{array}{l}\text { SCC method } \\
\text { [74] (Shanghai, }\end{array}$ & $\begin{array}{l}\text { TIBA } \\
\text { method }\end{array}$ \\
\hline Architecture & $\begin{array}{l}\text { Comfort } \\
\text { Health and } \\
\text { Space }\end{array}$ & $\begin{array}{l}\text { Built } \\
- \\
-\end{array}$ & $\begin{array}{l}- \\
- \\
-\end{array}$ & $\begin{array}{l}\text { Architectural } \\
- \\
-\end{array}$ & $\begin{array}{l}- \\
- \\
-\end{array}$ & $\begin{array}{l}\text { Health and } \\
- \\
-\end{array}$ \\
\hline Engineering & $\begin{array}{l}\text { High-tech image } \\
\text { Safety and } \\
\text { Working } \\
- \\
- \\
- \\
- \\
- \\
-\end{array}$ & $\begin{array}{l}\text { Functionality } \\
\text { Responsiveness } \\
\text { Suitability } \\
- \\
- \\
- \\
- \\
- \\
-\end{array}$ & $\begin{array}{l}\text { Automation } \\
\text { Comms } \\
\text { Security } \\
\text { Structure } \\
\text { Systems } \\
- \\
- \\
- \\
-\end{array}$ & $\begin{array}{l}\text { Electrical system } \\
\text { Info and comms } \\
\text { Mechanical } \\
\text { System. } \\
- \\
- \\
- \\
- \\
-\end{array}$ & $\begin{array}{l}\text { Conmunication } \\
\text { Earthing } \\
\text { Facility control } \\
\text { Fire accident } \\
\text { Int. integration } \\
\text { Office automation } \\
\text { Power supply } \\
\text { Security } \\
\text { Structured cabling }\end{array}$ & $\begin{array}{l}\text { Info and } \\
\text { Safety and } \\
\text { Structured } \\
\text { System. } \\
- \\
- \\
- \\
- \\
-\end{array}$ \\
\hline $\begin{array}{l}\text { Environment } \\
\text { Economics } \\
\text { Management } \\
\text { Sociology }\end{array}$ & $\begin{array}{l}\text { Green } \\
\text { Cost } \\
\text { Practice and } \\
\text { Culture }\end{array}$ & $\begin{array}{l}\overline{-} \\
\dot{-} \\
-\end{array}$ & $\begin{array}{l}- \\
- \\
\text { Property } \\
-\end{array}$ & $\begin{array}{l}\text { Environment } \\
- \\
\text { Facility } \\
-\end{array}$ & $\begin{array}{l}\text { Environment } \\
- \\
\text { Property } \\
-\end{array}$ & $\begin{array}{l}\text { Energy } \\
- \\
\text { Facilities } \\
-\end{array}$ \\
\hline
\end{tabular}

\section{Limitations of building rating methods}

One problem of current building rating methods is that they actually pay less attention to functional variation in different types of buildings, which influence not only the emotional as well as the physical well-being of human beings, but also the design and the management of buildings. In other words, each assessment procedure conducted under each rating method actually uses a generic platform of indicators applied to all kinds of buildings therefore do not differentiate one building from another regarding their various features. As a consequence, assessment results of different kinds of buildings actually lack the power of comparability regarding the features of IBs. For example, AIIB method adopts 29 sub-indicators to assess the performance of lift and escalators $[5,22]$; however, there is not a practical guide regarding how to compare two designs for one IB project if one uses a lift but another does not. It is not sensible to say buildings with a lift are more intelligent than buildings without them but a common generic platform will ensure all 
buildings have consideration given to aesthetics, function, convenience, flexibility, adaptability, reliability and health. In addition, the IBSK method [39] uses occupation density (occupation area for one person) as one indicator to assess Architectural Design of IBs, and the building with larger occupation area (a low occupation density) will get a higher score; however, one cannot say easily that a supermarket is much more intelligent than an office building because occupation area in supermarket is larger than that in an office building. In fact, buildings are classed according to their patterns of use at the design stage or management stage. For example, The Town and Country Planning (Use Classes) Order [59] regulates building class into four main categories with 16 classes depending on the purposes of building utilization in town and country planning and has been widely adopted in building design in the UK [4]. The NYC Building Classification Codes [64], on the other hand, provides a complete, comprehensive list of each Building Classification Code, and has been officially used to classify all properties and parcels from private homes to amusement parks by the City of New York. The lack of flexibility in current rating methods for IB assessment and the preference of classification in building design, construction and management indicate that innovations are required to develop flexible techniques for more objective assessment results of IBs.

Another problem of current building rating methods for IB assessment is that their calculation processes are not convincing enough to provide a reasonable assessment result. For example, the AIIB method, i.e. IB Index [5,22] aims to provide a quantitative composite approach to IB assessment using 10 indicator clusters based on the CobbDouglas utility function[112]. However, the recommended method for the IB Index calculation (see Eqs. (1) and (2) in Equations in Appendix A) is not actually reliable due to the following four reasons:

- the criteria of the AIIB method lead to non-determinism,

- the calculation method of the AIIB method is a non-sequitur,

- the calculation results from the AIIB method are non-unique, and

- the assessment procedure is based on non-organization principle/judgement.

Brief explanations to these reasons are given below:

The non-determinism led by the criteria of the AIIB method means that the assessment scores for each IB result from the evaluation criteria has questionable validity. As assessment results from each rating method depend upon a set of criteria denoted with a group of IB indicators, it is important to select the most appropriate group of indicators that are able to stand the test, and indicators adopted in a rating method that have less relevance to the IB will reduce the accuracy in assessments. For example, Special feature(s) recommended by the auditor is adopted in the AIIB method as an IB indicator in all most every category including Green, Space, Comfort, Working efficiency, High-tech image, Safety and structure, and Practice and Security. It is clear that different auditors will give different scores to these indicators even though all auditors deal with the same building because of their knowledge and their various understanding of the fuzzy definition during assessment. Based on this consideration, evaluations of IB indicators are of necessity required.

On the other hand, the AIIB method adopts, from the field of economics, the celebrated 
Cobb-Douglas utility function as its calculation method in the process of assessment [5, 22]. The Cobb-Douglas utility function is a standard utility function applied to describe matching output to input in a production processes and it is used commonly in both macroand micro-economics [108,109]. However, there is no clear information to support concerns about the application of the Cobb-Douglas utility function to the rating procedure according to personal discussions between the authors and other researchers in either the Cobb- Douglas utility function or rating procedure fields. In fact, the AIIB did not provide a reasonable explanation of reasons to adopt the Cobb-Douglas utility function in the calculation of a 10-module IB Index algorithm. Although the Cobb- Douglas utility function is one of the most widely applied utility functions in microeconomics, its major drawbacks such as the limited scope of effective regions and the harsh constraint terms to parameters definitely affect its utility in applications [10, 27, 37, 65, 97]. It is actually hard to define a physical model to describe this 10-module IB Index algorithm beyond the Cobb-Douglas utility function. Moreover, according to the second law of thermodynamics, which requires that any process that takes place at non-zero speeds must consume a minimum finite amount of exergy (the quality of energy), so production isoquants (combinations of inputs that yield the same output) [113] cannot be of the Cobb-Douglas type [40]. In these cases, the necessary and the sufficient conditions of applying the CobbDouglas utility function to the 10-module IB Index algorithm therefore require more study.

In addition, the AIIB method allows subjective weights of different building modules but this can lead to confusion about the interpretation of the assessment results. Table 2 recalls an example by the AIIB [5,22], in which the rate of weight comparison between two building modules are set as wx : wy $1 / 42: 1$, and the results of IB Index for each kind of building and the rank of their intelligence are in accordance with common intuition as to which kind of building is more intelligent. However, the function adopted in the IB Index calculation (refer to Eq. (3)) does not always lead to a sensible result. For example, let wx : wy $1 / 43: 1$, the IB Index values for each building are then different from the ones under wx : wy $1 / 42: 1$, and the sequence of building intelligence also changes (see Table 2). The AIIB method cannot provide a unique result, as different auditors may make different conclusions, which definitely cause complex- ity and variance in IB assessment.

Regarding the non-organization assessment procedure adopted in current building rating systems, the authors find that it is difficult to recognize Organization factors from current systems besides the Management cluster, in which only property management issues are concerned. Based on the summary in Table 1, the non-organization principle/ judgement existed in current building rating systems can definitely lead to partial assessments in which evaluators will miss their chance to study the culture, the structure and the occupants of all factors, which influence the performance of the building. 
Table 2 An experimental verification of the AIIB IB Index method

\begin{tabular}{|c|c|c|c|c|c|c|}
\hline \multirow[t]{2}{*}{ Buildings } & \multicolumn{2}{|l|}{ Scores } & \multicolumn{4}{|l|}{ IB Index } \\
\hline & Module $x$ & Module $y$ & $w x: w y=2: 1$ & $\begin{array}{l}\text { Rank of } \\
\text { intelligence }\end{array}$ & $w x: w_{y}=3: 1$ & $\begin{array}{l}\text { Rank of } \\
\text { intelligence }\end{array}$ \\
\hline B. Balanced Building & $\begin{array}{l}70 \\
60\end{array}$ & $\begin{array}{l}50 \\
60\end{array}$ & $\begin{array}{l}63 \\
60\end{array}$ & $\begin{array}{l}1 \\
2\end{array}$ & $\begin{array}{l}64 \\
60\end{array}$ & $\begin{array}{l}2 \\
3\end{array}$ \\
\hline C. Mechanical Plant & 100 & 20 & 59 & 3 & 69 & 1 \\
\hline D. Tree House & 20 & 100 & 34 & 4 & 30 & 4 \\
\hline
\end{tabular}

Theoretically speaking, logical defects in the currently used building rating methods, such as the IB Index method, may lead to an invalid IB assessment. It is thus required to provide an alternative method to evaluate the characteristics of IB, under objective and real life conditions, in which all indicators are taken into account, not only their values but also their interrelationships. In this respect, the authors put forward an alternative measure for IB assessment by means of analytic network process (ANP) [70-72]. In a test drive using the IB Index, the authors also noticed that 43 indicators (refer to Table 5) can be extracted from an integration of its 378 elements of 10 modules by using a quantitative indicator selection approach to be introduced below in Section 4. In fact, this integrative extraction also indicates that most elements adopted in the IB Index are repeated and need simplification. As mentioned above, the IB Index has a comprehensive classification of IB indicators, from which a most appropriate group of indicators can be selected for the ANP based assessment. In terms of the selection of indicators for assessing the lifespan energy efficiency of IBs, a quantitative evaluation approach will be put forward under the criteria of energy consumptions over time in which people, processes, and products are involved. To overcome the shortcomings that exist in the current IB Index method, the proposed IBAssessor can provide an innovative IB evaluation approach, in which both the value of indicators and their interrelations are taken into account.

\section{Quantitative selection of indicators}

\subsection{A SIBER model}

Lifespans of buildings include successive process stages in design, construction and operation relevant to their structural and services systems. The life cycle analysis/assessment (LCA) method is a quantitative approach to assess load magnitude in both natural and built environments in different patterns attributable to various influential factors at each stage of building systems [42]. The LCA method was introduced to the construction industry in 1970s [14, 82] in both structural engineering and project management. In the past 30 years, it has developed another main stream of assessment theory in the building and construction industry $[3,6,7,15,16,17,20,21,23,32,34,35,36,44-$ $46,49,50,51-57,61,62,63,66-69,77,78,83,90-96,98,105]$. For implementing the concept of LCA in project management, one essential is to benchmark construction processes; significant research and development progress have been achieved already. For example, the CSI [29] in the USA made a close loop of project cycle that describes five phases for construction projects including Planning and Predesign Activ- ities, Design Activities, 
Bidding Activities, Construction Activities, and Post-Construction Activities. Kagioglou et al. [48] in the UK developed a general Process protocol that describes ten phases for construction projects including Demonstrating the Need, Conception of Need, Outline Feasibility, Substantive Feasibility Study and Outline Financial Authority, Outline Conceptual Design, Full Conceptual Design, Co-ordinated Design, Procurement and Full Financial Authority, Production Information, Construction, and Operation and Maintenance. Smith [78] in the USA developed a knowledgebase support prototype for the Total Life-cycle Cost that describes ten phases for construction projects including Requirements, Plan, Program, Design, Construction, Operation, Maintenance, Evluation, Revitalization, and Disposal. The U.S. Army Corps of Engineers (USACE) conducted a series LCA research in 1990s [83-88] including the Guide for Project Partners and the Facility Composer. The Guide for Project Partners describes six basic phases of a civil works project including Reconnaissance, Feasibility, Pre-construction engineering and design, Real estate acquisition, Construction, and Operations and maintenance; and the Facility Composer is a suite of criteria/requirement-based facility modeling tools that integrate customer-specific criteria with a life-cycle facility model and commercial tools [79]. The Australian Building Codes Board [1] introduced energy efficiency performance standards into the Building Code of Australia in 2003 [76], in which Life Cycle House Energy Estimator [31] is adopted. Literature reviews indicate the process oriented LCA has been widely recognized and adopted in the building and construction industry, and become the basic view and starting point of construction management.

On the other hand, standards for quality assurance in business have been developed since late 1950s [75]. After the ISO [41-43] issued ISO 9000:1994 series of quality management standards and replaced with ISO 9000:2000, life-cycle business management has become a new development of LCA in construction management. For example, the USNIBS (1998) put forward a Total Life-cycle Cost Model for facilities managers to conduct the comparative evaluation of all costs, including productivity of function and impacts on the enterprise, health and the environment throughout the facilities life [78]. The FIDIC [33] introduced a Business Integrity Management System to set out why consultants should apply business integrity management in all of their work, and should introduce initiating the business integrity management process into their firms. Moreover, the USACE [86] developed a Project Management Business Process model to deliver quality projects. The model reflects the USACE corporate commitment to provide inclusive, seamless, flexible, effective, and efficient customer services, and embodies communication, leadership, systematic and coordinated management, teamwork, partnering, effective balancing of competing demands, and primary accountability for the life cycle of a project. Based on these LCA-based process benchmarks, Clements-Croome et al. [25] put forward the Through Life Environment Business Model (TLEBM) that concentrates upon six consistent phases for the business management of construction projects including Client Brief, Design, Installation/Commission (I/C), Operation and Maintenance (O\&M), Post Occupancy Evaluation (POE), and Reuse/Recycle/Disposal. In order to select the most appropriate indicators for intelligent building performance assessment, the authors integrate a Building Assessment entity with decision processes (decision-making options) into the TLEBM (refer to Fig. 1). There are three decision processes involved in the proposed decision-making model including a Design Review between the Design phase and the $I / C$ phase; an $I / C$ 
Review between the $I / C$ phase and the $O \& M$ phase; and an $O \& M$ Review between the $O \& M$ phase and the Disposal/Reusel Recycle phase, which is integrated with the POE phase. The new evolving process, which is a TLEBM based prototype for the lifespan performance assessment of buildings, is entitled SIBER, which is a Strategic Intelligent Building Evaluation and Renovation model.

In addition to the review of current rating systems, the authors are also planning a generic platform of IB assessment under the SIBER model, which is a representation of sustainable issues over the whole lifespan performance of buildings [25]. In this paper, the SIBER model will be used to effectively control a process in which a group of assessment indicators is quantitatively selected (refer to Fig. 2).

The SIBER model regulated assessment process requires a group of indicators, this will include quality of life factors that can effectively signify the sustainable lifespan performance of buildings for peoples. In this regard, three indicator clusters [11] are adopted to cover the whole range of indicators including the cluster for People, the cluster for Products, and the cluster for Processes; and all possible indicators are evaluated under restraining criteria of natural and social environmental factors before they can flow into the Indicator Cluster (refer to Fig. 1). In order to find the most appropriate indicators for the Building Assessment entity of the SIBER model under the restraining criteria, the authors create a quantitative energy-time based indicator evaluation approach, and introduce it below.

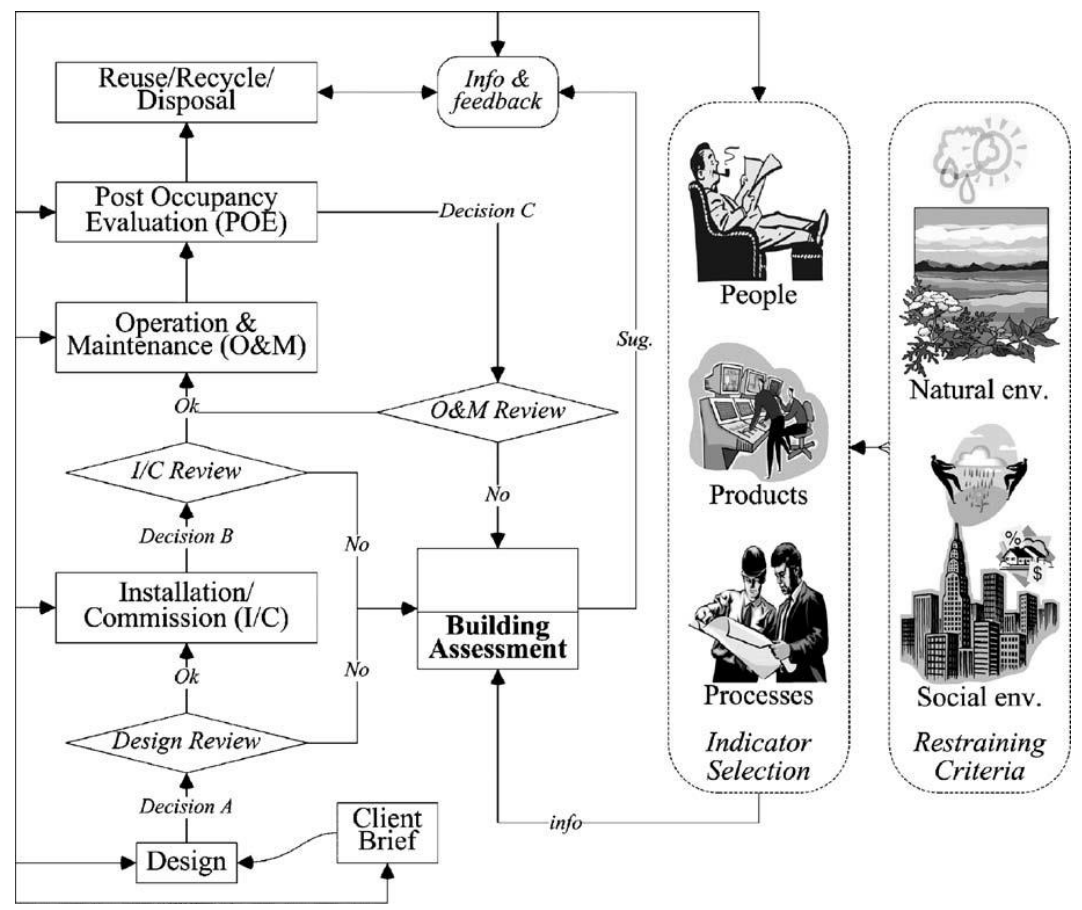

Fig. 1. The Strategic Intelligent Building Evaluation and Renovation (SIBER) model. 


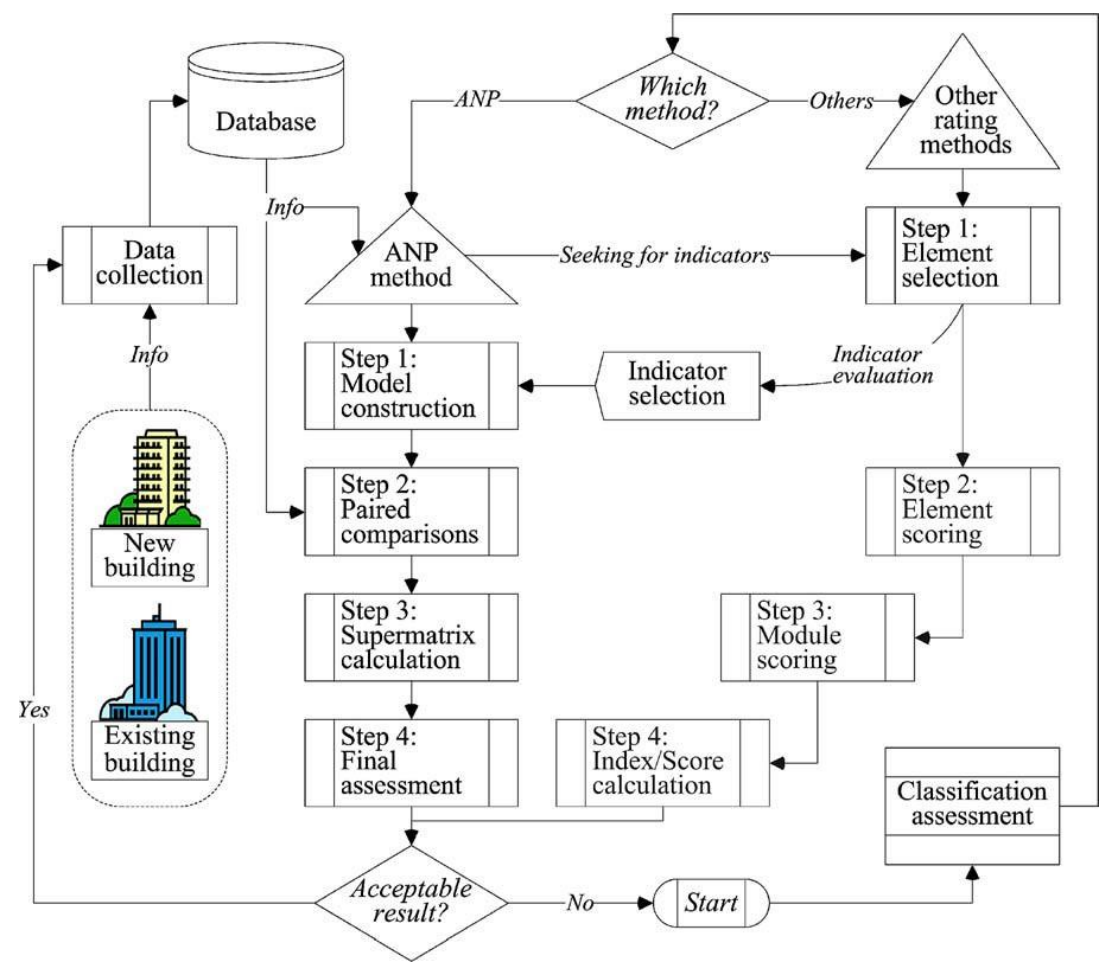

Fig. 2. The Tactical Intelligent Building Evaluation and Renovation (TIBER) model.

\subsection{An energy-time consumption index}

It is generally accepted that both energy and time consumptions exist in each process, in term of Products and Processes, for any building component or building system to fulfill all kinds of requirements for People. Regarding the energy consumption, embodied energy is one important measurement. Embodied energy is the energy consumed by all of the procedures associated with the production of a building, from the acquisition of natural resources to product delivery, including mining, manufacturing of materials and equipment, transport and administrative functions [26]. Previous research that focus on the LCA of cost and environmental impacts of construction projects include the embodied energy of products such as material, component, equipment and building [13,15,16,80,81,110]; and the processes such as construction, installation and maintenance $[28,38,47,60]$. Although the time factor features in project management, the speed of energy consumption is disregarded in previous LCA research based on the embodied energy. However, it is important to measure the velocity of energy consumptions in producing and processing in accordance with the performance of IBs as required by people. Because the environment itself has power but needs time to eliminate pollutants [107,111], and a high-energy consumption in a long lifespan may not be more adverse to the environment than a relatively low energy consumption over a short period. In this regard, a quantitative measurement for selecting indicators, called ETI is put forward by means of an embodied energy consumption rate (see Eqs. (4) and (5)). This reflects the idea of energy intensity being important. 


$$
\begin{aligned}
& F_{\mathrm{ETI}}=f(e, t) \\
& \mathrm{ETI}_{i}=\frac{\partial F_{\mathrm{ETI}_{i}}}{\partial t}
\end{aligned}
$$

Eq. (4) gives a normal expression of ETI function (FETI)consisting of two variables including energy (e) and time (t); Eq. (5) gives a normal calculation method of the ETI for whichever indicator $i$, and is a partial time derivative of Eq. (4). The application of Eq. (5) depends on a specific function to describe the dependent relation with energy and time variables for the ETI. As there is not enough statistical data to mine and formulate such a function at this moment, the authors propose an alternative simplified approach to calculate the ETI (refer to Eq. (6) in Equations).

$$
\mathrm{ETI}_{i}=\frac{\sum_{j=1}^{2} \mathrm{SEC}_{i, j}}{\sum_{j=1}^{2} \mathrm{STC}_{i, j}}
$$

In Eq. (6), $\mathrm{ETI}_{i}$ is the ETI of indicator $i$; $\mathrm{SEC}_{i, j}$ is the score of energy consumption (SEC) of indicator $i$ relevant to Indicator Cluster $j(j=1$ or 2 , corresponding to the two Indicator Cluster which include Products Cluster $(j=1)$ and Processes Cluster $(j=2)$ ); $\mathrm{STC}_{i, j}$ is the score of time consumption (STC) of indicator $i$ relevant to Indicator Cluster $j$. The set of $\mathrm{SEC}_{i, j}$ is based on consideration that the energy embodied into a product covers a period of time during a process. To further regulate the selection of indicators, the authors subjectively define the fundamental scales as given in Table 3 in accordance with the

\begin{tabular}{|c|c|c|c|}
\hline \multicolumn{2}{|l|}{ Scales for scoring } & Products (embodied energy/time pattern) & Processes (operational energy/time pattern) \\
\hline \multicolumn{2}{|c|}{ Score of energy consumption $\left(\mathrm{SEC}_{i, j}\right)$} & \multirow[t]{6}{*}{$\begin{array}{l}\text { Embodied energy of products } \\
\text { in manufacture, construction and installation }\end{array}$} & \multirow[t]{6}{*}{$\begin{array}{l}\text { Energy required in operation processes } \\
\text { upon People' occupancy requirements }\end{array}$} \\
\hline $1=$ extremely low & $6=$ high & & \\
\hline $2=$ very strongly low & $7=$ moderately high & & \\
\hline $3=$ strongly low & $8=$ strongly high & & \\
\hline $4=$ moderately low & $9=$ very strongly high & & \\
\hline $5=$ low & $10=$ extremely high & & \\
\hline \multicolumn{2}{|c|}{ Score of time consumption $\left(\mathrm{STC}_{i, j}\right)$} & \multirow[t]{4}{*}{$\begin{array}{l}\text { Time requirements in product making in } \\
\text { manufacture, construction and installation }\end{array}$} & \multirow[t]{4}{*}{$\begin{array}{l}\text { Time required in operation processes } \\
\text { upon People' occupancy requirements }\end{array}$} \\
\hline $1=(0,1$ day $]$ & $4=(1$ month, 1 year $]$ & & \\
\hline $2=(1$ day, 1 week $]$ & $5=>1$ year & & \\
\hline $3=(1$ week, 1 month $]$ & & & \\
\hline
\end{tabular}
values of $\mathrm{SEC}_{i, j}$ and $\mathrm{STC}_{i, j}$.

Table 3 Fundamental scales of the sores and relevant descriptions of energy/time consumptions

Based on the fundamental scale of the scores of energy and time consumptions given in Table 3 , the ETI score of each indicator, i.e. Indicator $i$, can have its value regarding energy and time consumptions in a scoring form (see Table 4). Generally, the $\mathrm{ETI}_{i, \max }=1000$ and the $\mathrm{ETI}_{i, \min }=$ 20 (refer to Tables 3 and 6). As mentioned in Section 2, the IB Index has a comprehensive category of indicators for assessing IBs. In this regard, the authors chose it as a model for scoring ETI, and therefore chose a group of ETI-scored indicators for the proposed BAssessor ANP model. Because the ETI is a general approach to selecting indicators under the criteria 
of building sustainability, it is suggested that a furthercomplete evaluation of IB indicators is made for the IBAssessor ANP model based on current building rating systems as mentioned in Section 2. This paper only demonstrates the usability of ETI and the IBAssessor ANP model. Table 5 gives a result from ETI-scored indicator evaluation based on the IB Index. At Reading University and HK Polytechnic University, further development of this model is taking place.

Table 4 The scoring form of Indicator $i$ regarding its energy and time consumptions

\begin{tabular}{lllll}
\hline & Produ & Process & Subtotal & Total \\
\hline Energy consumption score & $\left(\mathrm{SEC}_{i,}\right.$ & $\left(\mathrm{SEC}_{i, 2}\right)$ & $\left(\mathrm{SEC}_{i}\right)$ & \\
Time consumption score & $\left(\mathrm{STC}_{i, 1}\right)$ & $\left(\mathrm{STC}_{i, 2}\right)$ & $\left(\mathrm{STC}_{i}\right)$ & $\left(\mathrm{ETI}_{i}\right)$ \\
\hline
\end{tabular}

Table 5 Selected indicators using ETI based on the IB Index

\begin{tabular}{|c|c|c|c|c|c|c|c|c|}
\hline Indicator & IB Index code & $\mathrm{SEC}_{i, 1}$ & $\mathrm{SEC}_{i, 2}$ & $\mathrm{SEC}_{i}$ & $\mathrm{STC}_{i, 1}$ & $\mathrm{STC}_{i, 2}$ & $\mathrm{STC}_{i}$ & $\mathrm{ETI}_{i}$ \\
\hline Electricity and electrical services & GRI25 & 7 & 5 & 12 & 1 & 5 & 6 & 200 \\
\hline Heating services & GRI27 & 7 & 9 & 16 & 3 & 5 & 8 & 200 \\
\hline Ventilation and air conditioning & GRI31 & 6 & 9 & 15 & 3 & 5 & 8 & 188 \\
\hline Building services automation & HTI25 & 9 & 7 & 16 & 4 & 5 & 9 & 178 \\
\hline Construction materials & HTI35 & 8 & 8 & 16 & 4 & 5 & 9 & 178 \\
\hline IT\&C facilities and services & WEI30 & 8 & 6 & 14 & 3 & 5 & 8 & 175 \\
\hline Thermal comfort and indoor air & GRI22 & 5 & 8 & 13 & 3 & 5 & 8 & 163 \\
\hline Lifts/escalators and controls & GRI02 & 5 & 8 & 13 & 3 & 5 & 8 & 163 \\
\hline Security and safety control & SSI19 & 6 & 5 & 11 & 3 & 5 & 8 & 138 \\
\hline Reserve electric power & SSI26 & 7 & 3 & 10 & 3 & 5 & 8 & 125 \\
\hline Green materials & MPS18 & 5 & 5 & 10 & 3 & 5 & 8 & 125 \\
\hline Flushing water system & HSI07 & 6 & 4 & 10 & 3 & 5 & 8 & 125 \\
\hline External decoration & SSI05 & 5 & 6 & 11 & 4 & 5 & 9 & 122 \\
\hline Building architectural design & HTI28 & 4 & 2 & 6 & 4 & 1 & 5 & 120 \\
\hline Lavatory accommodation & GRI18 & 4 & 5 & 9 & 3 & 5 & 8 & 113 \\
\hline Refuse collection & HSI21 & 5 & 4 & 9 & 3 & 5 & 8 & 113 \\
\hline Circulation for the disabled & SSI11 & 5 & 5 & 10 & 4 & 5 & 9 & 111 \\
\hline Computer aided & MPS03 & 2 & 8 & 10 & 4 & 5 & 9 & 111 \\
\hline Waste disposal & GRI64 & 1 & 2 & 3 & 1 & 2 & 3 & 100 \\
\hline Flexibility for renovation & SPI15 & 4 & 3 & 7 & 2 & 5 & 7 & 100 \\
\hline Internal decoration & CLI03 & 4 & 4 & 8 & 3 & 5 & 8 & 100 \\
\hline Structural monitoring and control & SSI04 & 4 & 4 & 8 & 3 & 5 & 8 & 100 \\
\hline Computer aided manufacturing & MPS03 & 8 & 1 & 9 & 4 & 5 & 9 & 100 \\
\hline Potable water system & HSI01 & 5 & 3 & 8 & 3 & 5 & 8 & 100 \\
\hline Green design & MPS01 & 6 & 2 & 8 & 4 & 5 & 9 & 89 \\
\hline Lighting & GRI45 & 4 & 3 & 7 & 3 & 5 & 8 & 88 \\
\hline Fire detection and resistance & SSI13 & 4 & 3 & 7 & 4 & 4 & 8 & 88 \\
\hline Cleanliness & HSI20 & 4 & 3 & 7 & 3 & 5 & 8 & 88 \\
\hline Property management & WEI70 & 1 & 5 & 6 & 2 & 5 & 7 & 86 \\
\hline Computer aided design & MPS02 & 5 & 2 & 7 & 4 & 5 & 9 & 78 \\
\hline Carpark/transportation facilities & SPI06 & 2 & 3 & 5 & 2 & 5 & 7 & 71 \\
\hline Entertainment facilities & CFI48 & 1 & 4 & 5 & 2 & 5 & 7 & 71 \\
\hline External landscape & CLI07 & 2 & 3 & 5 & 2 & 5 & 7 & 71 \\
\hline
\end{tabular}




\begin{tabular}{llllllllc}
\hline Indicator & IB Index code & SEC $_{i, 1}$ & SEC $_{i, 2}$ & SEC $_{i}$ & STC $_{i, 1}$ & STC $_{i, 2}$ & STC $_{i}$ & ETI $_{i}$ \\
\hline Extensive use of artificial & HTI31 & 4 & 2 & 6 & 4 & 5 & 9 & 67 \\
Electromagnetic compatibility & GRI66 & 3 & 1 & 4 & 2 & 5 & 7 & 57 \\
Environmental friendliness & GRI53 & 1 & 2 & 3 & 1 & 5 & 6 & 50 \\
Conference and meeting facilities & WEI77 & 1 & 3 & 4 & 3 & 5 & 8 & 50 \\
Drainage & GRI65 & 2 & 1 & 3 & 2 & 5 & 7 & 43 \\
Existence of green features & GRI01 & 1 & 1 & 2 & 1 & 5 & 6 & 33 \\
Access sign and directory & WEI61 & 1 & 1 & 2 & 1 & 5 & 6 & 33 \\
Maintainality & SSI28 & 1 & 1 & 2 & 1 & 5 & 6 & 33 \\
Usable areas & SPI01 & 1 & 1 & 2 & 2 & 5 & 7 & 29 \\
Means of escape & SSI14 & 1 & 1 & 2 & 3 & 5 & 8 & 25 \\
\hline
\end{tabular}

Note: Green Index (GRI), Space Index (SPI), Comfort Index (CFI), Working Efficiency Index (WEI), Culture Index (CLI), High-tech Image Index (HTI), Safety and Structure Index (SSI), Management Practice and Security (MPS), Cost Effectiveness Index (CEI), Health and Sanitation Index (HSI).

\subsection{Key performance indicators}

There are 378 elements under 10 modules of the IB Index, including a Green Index (GRI) module, a Space Index (SPI) module, a Comfort Index (CFI) module, a Working Efficiency Index (WEI) module, a Culture Index (CLI) module, a High- tech Image Index (HTI) module, a Safety and Structure Index (SSI) module, a Management Practice and Security Index (MPS) module, a Cost Effectiveness Index (CEI), and a Health \& Sanitation Index (HSI) module. As summarized in Table 5, 43 indicators emerge from these 378 indicators following the ETI based identification. To finally select a group of key performance indicators (KPIs) for the ANP model, the authors further estimate the scope of ETI, i.e. $\mathrm{ETI}_{i, \max }=1000$ and the ETI $i$,min $=20$, based on Gann's Square of Nine [106] (refer to Table 6). The purpose of this study is to explain concisely but in detail simple mathematical and graphical techniques for applying Gann's Square of Nine to KPI selection.

Table 6 Gann's square of nine [106] for KPI identification

\begin{tabular}{|l|c|c|c|c|c|c|c|c|c|}
\hline & 1000 & 990 & 980 & $\mathbf{9 7 0}$ & 960 & 950 & 940 & 930 & $\mathbf{9 2 0}$ \\
\hline $\mathbf{6 6 0}$ & 650 & 640 & 630 & $\mathbf{6 2 0}$ & 610 & 600 & 590 & $\mathbf{5 8 0}$ & 910 \\
\hline 670 & $\mathbf{3 8 0}$ & 370 & 360 & $\mathbf{3 5 0}$ & 340 & 330 & $\mathbf{3 2 0}$ & 570 & 900 \\
\hline 680 & 390 & $\mathbf{1 8 0}$ & 170 & $\mathbf{1 6 0}$ & 150 & $\mathbf{1 4 0}$ & 310 & 560 & 890 \\
\hline 690 & 400 & 190 & $\mathbf{6 0}$ & $\mathbf{5 0}$ & $\mathbf{4 0}$ & 130 & 300 & 550 & 880 \\
\hline $\mathbf{7 0 0}$ & $\mathbf{4 1 0}$ & $\mathbf{2 0 0}$ & $\mathbf{7 0}$ & $\mathbf{2 0}$ & $\mathbf{3 0}$ & $\mathbf{1 2 0}$ & $\mathbf{2 9 0}$ & $\mathbf{5 4 0}$ & $\mathbf{8 7 0}$ \\
\hline 710 & 420 & 210 & $\mathbf{8 0}$ & $\mathbf{9 0}$ & $\mathbf{1 0 0}$ & 110 & 280 & 530 & 860 \\
\hline 720 & 430 & $\mathbf{2 2 0}$ & 230 & $\mathbf{2 4 0}$ & 250 & $\mathbf{2 6 0}$ & 270 & 520 & 950 \\
\hline 730 & $\mathbf{4 4 0}$ & 450 & 460 & $\mathbf{4 7 0}$ & 480 & 490 & $\mathbf{5 0 0}$ & 510 & 840 \\
\hline $\mathbf{7 4 0}$ & 750 & 760 & 770 & $\mathbf{7 8 0}$ & 790 & 800 & 810 & $\mathbf{8 2 0}$ & 830 \\
\hline
\end{tabular}

The Gann's Square of Nine [106] for KPI selection is constructed using a grid of numbers that begins in the centre with number 20 in accordance with the value of $\mathrm{ETI}_{i, \min }$. The 
number 30 goes to the box to the right of the number 20. Moving up and round anticlockwise, 10 is added to the previous number and the resulting number goes to the box. This is repeated in a spiral around the centre. There are two crosses in the developed grid, including a Cardinal Cross and a Fixed Cross. The Cardinal Cross is composed of the vertical and horizontal rows that intersect at the middle of the square; the line extending at 458 constitutes the Fixed Cross. The Cardinal Cross and Fixed Cross are used to determine likely points of ETI related to KPIs. Table 6 gives the results of the Square of Nine for KPI identification.

Based on these results, KPIs for IB assessment are finally divided into five ETI aggregations, i.e. [20,100], (100, 260], $(260,500],(500,820]$, and $(820,1000]$. In accordance with these aggregations, five groups of KPIs, i.e. KPI Group $t(t=1-5)$ can be defined. Among the 43 indicators as summarized in Table 5, 18 indicators are recognized as KPI Group 1 with their ETI scores above 100 but below 260, i.e. 260 2: $\mathrm{ETI}_{i}>100 ; 25$ indicators are allocated to KPI Group 2 with their ETI scores below 100 but including 100, i.e. 100 2: ETI $_{i}>0$. The ETI scores presented in Table 5 are calculated using Eq. (6) and the score of energy-time consumption (SEC/STC), which can be compared with experts' opinions. As a result, two groups of KPIs for IBAssessor model are identified based on the IB Index (refer to Table 8).

\section{IBAssessor approach}

Developed by Saaty [70-72], the ANP is a general theory of relative measurement used to derive composite priority ratio scales from individual ratio scales that represent relative measurements of the influence of elements that interact with respect to control criteria. An ANP model consists of two parts including a network of interrelationships among each two nodes or clusters, and a control network of criteria/subcriteria that control interactions based on interdependencies and feedback. In order to conduct decision-making process, a control hierarchy is generally employed to build an ANP model. The control hierarchy is a hierarchy of criteria and subcriteria for which priorities are derived in the usual way with respect to the goal of a system being considered. The criteria are used to compare the clusters of an ANP model, and the subcriteria are used to compare the nodes of a cluster. Regarding how to conduct IB assessment by using ANP, Fig. 2 illustrates a four-step ANP procedure, in which the SIBER model (refer to Fig. 1) based ETI supported indicator selection process is integrated, and the ANP based IB assessment model presented in Fig. 2 is called TIBER model.

There are four general steps in ANP based multicriteria decision-making process: model construction; paired comparisons between each two clusters or nodes; supermatrix calculation based on results from paired comparisons; and result analysis for the assessment. As a frame of reference, Fig. 2 also summaries a four-step procedure for AIIB method, which is regarded as one important source of indicators for IB assessment to support building an ANP model. For users who want to conduct IB assessment, Fig. 2 provides two options to either use ANP method or other rating methods. Based on their evaluation theory, the rating methods such as the AIIB method can only be used to evaluate one IB each time, whilst the ANP method can be used to evaluate either one IB or several IBs. To evaluate several IBs together each time, information of a reference IB such as a standard IB in a 
particular building class or alternative building plans for a same IB has to be added to the ANP model. To achieve this, Fig. 2 also illustrates how the ANP method retrieves information from other rating methods and rating systems to collect information for IB assessment. As all other rating methods such as AIIB method [5, 22] and IBSK method [39] have their own developed IB indicators, it is therefore useful and important for ANP model construction. In addition to the parallel assessment procedures between the rating method and the ANP method, Fig. 2 proposes an assessment database, which is essential for an ANP model development loop including processes of model construction, model evaluation, model revision and model reuse. The proposed IB database can also provide information of a standard IB when the ANP model is used to assess a building comparing with a standard building in the same building class; otherwise, an alternative of the building has to be presented to support the assessment. However, this paper will not discuss how to develop such an IB database to support ANP-based assessment, and will focus on the procedure of IB assessment using ANP method and the group of indicators collected from the ETI based selection.

\subsection{Step A: ANP model construction \\ 5.2.}

The objective of Step A is to build an ANP model for IB assessment. The ANP model is built based on determining the control hierarchies, as well as the corresponding criteria for comparing the clusters, including subclusters, of the model and sub-criteria for comparing the nodes inside each cluster and each subcluster, together with a determination of clusters and subclusters with their nodes for each control criteria or subcriteria. Before finalising an ANP model, a set of indicators for the model construction has to be defined. As the purpose of this paper is to provide an alternative approach for IB assessment based on the IB Index $[5,22]$, the group of KPIs identified in Section 4 is therefore selected for the proposed ANP model. Fig. 3 gives an outline of the proposed IBAssessor ANP model.

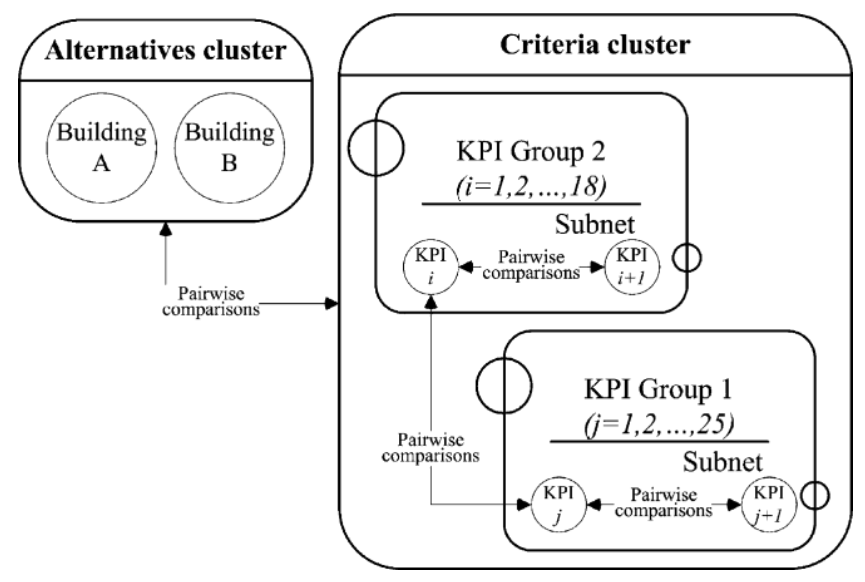

Fig. 3. The IBAssessor ANP model.

There are two clusters inside the IBAssessor model, including one Criteria cluster and one Alternatives cluster. The goal of the IBAssessor model is to select the most appropriate IB from several alternatives in the process of evaluation or to make a comparison between a 
proposed IB and a standard IB in a same catalogue in the process of assessment. In correspondence with this goal, the cluster of Alternatives (denoted as $C_{\text {selection})}$ consists of two nodes in this paper including Building A and Building B, which are two IB candidates to be evaluated by the IBAssessor. On the other hand, the Criteria cluster contains two Subnets including the subcluster of KPI Group $t(t=1,2)$ (denoted as $\left.C_{\mathrm{KPIG} t}\right)$. Inside these two subclusters, the KPI Group 2 subcluster consists of 18 nodes (i.e. KPI $i(i=1,2, \ldots, 18)$ ) in accordance with the 18 indicators of KPI Group 2, and the KPI Group 1 subcluster consists of 25 nodes (i.e. KPI $j(j=1,2, \ldots, 25)$ ) in accordance with the 25 indicators of KPI Group 1. All these KPIs involved in the Criteria cluster are collected based on the ETI evaluation of the IB Index [5, 22] (refer to Tables 5 and 8).

In accordance with these two clusters and their total 45 nodes, the IBAssessor ANP model is thus set up with interrelation connectivity between each two clusters and their nodes. Connections inside the two clusters finally generate a network with interrelations among clusters, subclusters and nodes (refer to Table 9) including the Alternatives cluster (with two nodes), the KPI Group 2 subcluster (with 18 nodes), and the KPI Group 1 subcluster (with 25 nodes). The network connections are modelled by using one- or two-way arrows and looped arrows to describe the interdependences that exist between each two clusters or subclusters and each two nodes (refer to Fig. 3).

\subsection{Step B: paired comparisons}

The objective of step B is to carry out pairwise comparisons among clusters and subclusters, as well as pairwise comparisons between each two nodes, because they are interdependent on each other during the lifespan of IBs. The pairwise comparison is a quantitative description approach to interrelation connections illustrated in the IBAssessor ANP model (refer to Fig. 3). In order to complete pairwise comparisons, the relative importance weight, denoted as $a_{i j}$, of interdependence is determined by using a scale of pairwise judgements, where the relative importance weight is valued from 1 to 9 [70]. Table 7 reproduces the fundamental scale of pairwise judgements generally applied in pairwise comparisons.

Table 7 Scale of pairwise judgement [70]

\begin{tabular}{ll}
\hline Pairwise judgement & Scale \\
Equal & 1 \\
Equally to moderately dominant & 2 \\
Moderately dominant & 3 \\
Moderately to strongly dominant & 4 \\
Strongly dominant & 5 \\
Strongly to very strongly dominant & 6 \\
Very strongly dominant & 7 \\
Very strongly to extremely dominant & 8 \\
Extremely dominant & 9 \\
\hline
\end{tabular}


Decision makers with professional experience and knowl- edge can use these scales for pairwise comparisons to determine the weight of interdependence. In this study, the authors determine this because the objective of this study is mainly to demonstrate the process and usefulness of the ANP model for IB assessment; in practice, the building design team will make these comparisons. Table 8 gives some details for the case study.

Table 8 A case details about KPI and their values for the IB Assessor model

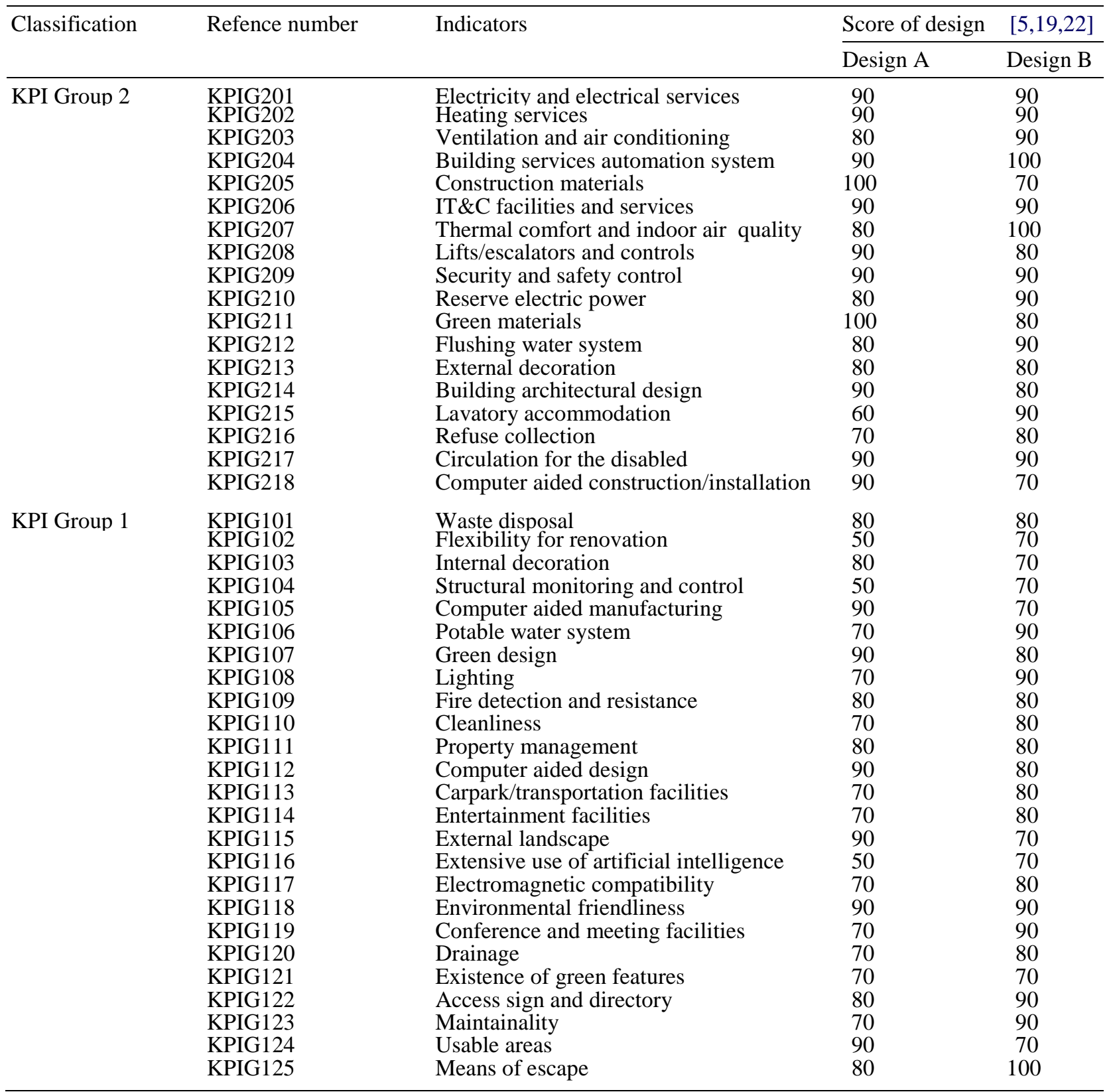

Table 9 gives a general form for pairwise judgement between each two nodes inside the IBAssessor ANP model. There are two types of pairwise judgements, one is the pairwise comparison between a KPI and a building alternative, and another is the pairwise 
comparison between two KPIs. As an example, for the node KPIG203, i.e. ventilation and air- conditioning (refer to Table 8), the pairwised judgements are given in Table 9, in which the scale for Building $\mathrm{B}$ is 8 , whilst it is 4 for Building A, because the use of natural ventilation in Building $A$ is less than in Building $B$ (refer to Table 9). In this regard, quantitative pairwise judgements can thus be conducted in order to define priorities of each indicator for each IB Candidate, and the judgements are based on the quantitative attribute of each indicator from each IB Candidate (refer to Table 8). Besides the pairwise judgement between an indicator and an IB Candidate, the IBAssessor model also contains all other pairwise judgements between each indicator. For example, Indicator $I_{i}$ (KPIG203 as a representative) is very strongly dominant to Indicator $I_{j}$ (KPIG111 as a representative); therefore the judgement value equals seven (as shown in Table 9). In summary, the essential initialization for ANP modelling is set up based on the quantitative attribute (as described in Table 8) of indicators for each IB Candidate and inherent characteristics of each indicators.

Table 9 Pairwise judgement of indicator $I_{i}$ (KPIG203) and $I_{j} \quad$ (KPIG111)

\begin{tabular}{lllllllllll}
\hline Pairwise & & 1 & 2 & 3 & 4 & 5 & 6 & 7 & 8 & 9 \\
\hline Indicator $I_{i}$ & Building A & $\mathrm{X}$ & $\mathrm{X}$ & $\mathrm{X}$ & $\sqrt{ }$ & $\mathrm{X}$ & $\mathrm{X}$ & $\mathrm{X}$ & $\mathrm{X}$ & $\mathrm{X}$ \\
& Building B & $\mathrm{X}$ & $\mathrm{X}$ & $\mathrm{X}$ & $\mathrm{X}$ & $\mathrm{X}$ & $\mathrm{X}$ & $\mathrm{X}$ & $\sqrt{ }$ & $\mathrm{X}$ \\
Indicator $I_{i}$ & ${\text { Indicator } I_{j}}$ & $\mathrm{X}$ & $\mathrm{X}$ & $\mathrm{X}$ & $\mathrm{X}$ & $\mathrm{X}$ & $\mathrm{X}$ & $\sqrt{ }$ & $\mathrm{X}$ & $\mathrm{X}$
\end{tabular}

Note: The fundamental scale of pairwise judgement is given in Table 7. The symbol (X) denotes item under selection for pairwise judgement, and the symbol $(\sqrt{ })$ denotes selected pairwise judgement.

\subsection{Step C: supermatrix calculation}

This step aims to form a synthesized supermatrix to allow for a resolution based on the effects of the interdependences that exist between the elements (including nodes, subclusters and clusters) of the IBAssessor ANP model. The supermatrix is a twodimensional partitioned matrix consisted of one nine submatrices (refer to Table 10).

Weights defined from pairwise judgements for all inter- dependences for each individual IB Candidate are then aggregated into a series of submatrices. For example, if the Alternative cluster and its nodes are connected to nodes in the subcluster KPI Group 1 (denoted as $C_{\mathrm{KPIG} 1}$ ), pairwise judgements of the cluster thus result in relative weights of importance between each IB Candidate and each indicator inside the KPI Group 1 subcluster. The aggregation of the determined weights thus forms a $2 \times 25$ submatrix located at " $W_{13}$ " and " $W_{31}$ " in Table 10 . It is necessary to note that pairwise comparisons are necessary to all connections among each node, subcluster and cluster in the IBAssessor ANP model to identify the level of interdependences, which are fundamental in the ANP procedure. Upon the completion of pairwise judgements, the nine submatrices are then aggregated into a supermatrix, which is denoted to supermatrix A in this study (refer to Table 10). And it is then used to derive the initial supermatrix in the later calculation in Step C, and the calculation of the IBAssessor ANP model can thus be conducted following Step C to D. 
Table 10 Formulation of supermatrix and its submatrix for IBAssessor ANP model

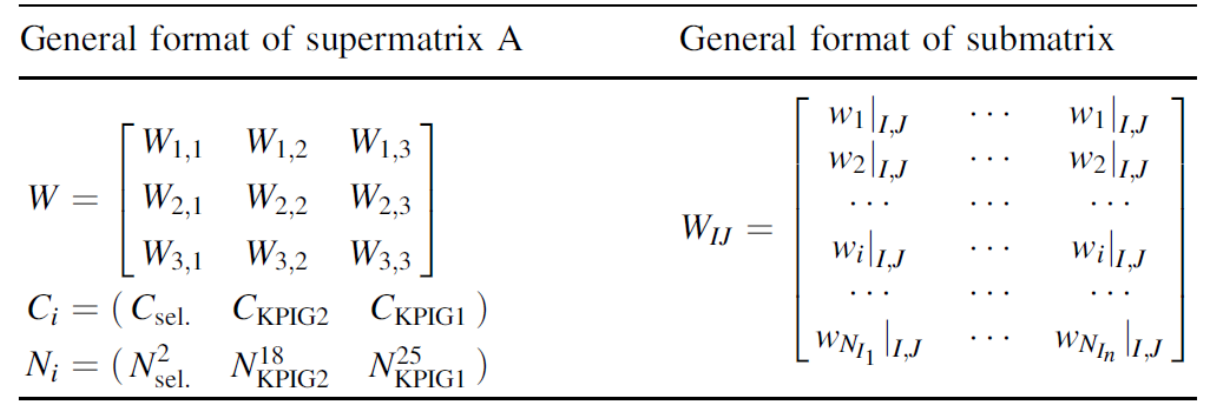

Note: $\mathrm{I}$ is the index number of rows; and $\mathrm{J}$ is the index number of columns; both $\mathrm{I}$ and $\mathrm{J}$ correspond to the number of cluster and their nodes (I, J $2(1,2, \ldots, 45))$, NI is the total number of nodes in cluster I, $\mathrm{n}$ is the total number of columns in cluster I. Thus, a $45 * 45$ supermatrix is formed.

In order to obtain useful information for IB assessment, the calculation of supermatrix is to be conducted following three substeps, which transform an initial supermatrix to a weighted supermatrix, and then to a synthesized supermatrix.

At first, an initial supermatrix of the IBAssessor model is created. The initial supermatrix consists of local priority vectors obtained from the pairwise comparisons among clusters and nodes. A local priority vector is an array of weight priori- ties containing a single column (denoted as wT $=[\mathrm{w} 1, \ldots$, wi, ..., wn $]$ ), whose components (denoted as wi) are derived from a judgment comparison matrix A and deduced by Eq. (7) [70-72].

$$
\left.w_{i}\right|_{I, J}=\frac{\sum_{i=1}^{I}\left(\alpha_{i j} / \sum_{j=1}^{J} \alpha_{i j}\right)}{J}
$$

Where $\left.\mathrm{w}\right|_{\mathrm{I}, \mathrm{J}}$ is the weighted/derived priority of node $\mathrm{i}$ at row I and column $\mathrm{J}$; $\mathrm{a}_{\mathrm{ij}}$ is a matrix value assigned to the interdependence relationship of node $i$ to node $j$. The initial supermatrix is constructed by substituting the submatrices into the supermatrix as indicated in Table 10. A detailed initial supermatrix is not given in this paper.

After formating the initial supermatrix, a weighted supermatrix is then transformed. This process is to multiply all nodesin a cluster of the initial supermatrix by the weight of the cluster, which has been established by pairwise comparison among clusters. In the weighted supermatrix, each column is stochastic, i.e. sum of the column amounts to 1 [70-72].

The last substep of supermatrix calculation is to compose alimiting supermatrix, which is to raise the weighted supermatrix to powers until it converges/stabilizes when all the columns in the supermatrix have the same values. Saaty [70] indicated that as long as the weighted supermatrix is stochastic, a meaningful limiting result could be obtained for prediction.

The approach to arrive at a limiting supermatrix is by taking repeatedly the power of the matrix, i.e. the original weighted supermatrix, its square, and its cube, etc., until the limit is attained (converges), in which case the numbers in each row will all become identical. A calculus type algorithm is employed in the software environment of Super Decisions by Bill Adams and the Creative Decision Foundation to facilitate the formation of the limiting supermatrix and the calculation result is omitted in this paper. As the limiting supermatrix is 
set up, the following step is to select a proper plan alternative using results from the limiting supermatrix.

Table 11 Selection of the most appropriate IB

\begin{tabular}{lllll}
\hline Model & $\begin{array}{l}\text { Number } \\
\text { of nodes }\end{array}$ & \multicolumn{2}{l}{ Synthesized priority weight $W_{i}$} & Selection \\
\cline { 3 - 4 } & Building A & Building B & \\
\hline IBAssessor & 45 & 0.44 & 0.56 & Building B \\
\hline
\end{tabular}

\subsection{Step D: selection}

This step aims to select the most appropriate IB Candidate based on the computation results from the limiting supermatrix of the IBAssessor model. Main results of the ANP model computations are the overall priorities of IB Candidates obtained by synthesizing the priorities of individual IB Candidate against different KPIs. The selection of the most appropriate IB Candidate that has the highest priority of lifespan energy efficiency is conducted by a limiting priority weight, which is defined in Eq. (8).

$$
W_{i}=\frac{w_{\mathrm{C}_{\mathrm{BB}}, i}}{w_{\mathrm{C}_{\mathrm{IB}}}}=\frac{w_{\mathrm{C}_{\mathrm{IB}}, i}}{\sum_{i} w_{\mathrm{C}_{\mathrm{IB}}, i}}
$$

where $\mathrm{Wi}$ is the synthesized priority weight of IB Candidate $\mathrm{i}(\mathrm{i}=1, \ldots, \mathrm{n})$ ( $\mathrm{n}$ is the total number of IB Candidates, $\mathrm{n}=2$ in this study), and $\mathrm{w}_{\mathrm{CIB}, \mathrm{i}}$ is the limited weight of IB Candidate $\mathrm{i}$ in the limiting supermatrix. Because the $\mathrm{w}_{\mathrm{CIB}}, \mathrm{i}$ is transformed from pairwise judgements conducted in Step B, it is reasonable to be treated as the priority of IB Candidate $\mathrm{i}$ and thus to be used in Eq. (8). According to the computation results in the limiting supermatrix, $\mathrm{W}_{\mathrm{CIB}, \mathrm{i}}=(0.433 ; 0.561)$, so the $\mathrm{Wi}=(0.44,0.56)$, as a result, the most appropriate IB is Candidate B (refer to Table 11).

According to the attributes of each IB Candidate listed in Table 8, the comparison results using Wi also implies that the most preferable building is the candidate that regulates the building performance of lifespan energy efficiency with best solutions for building services systems, least energy consumption, lowest ratio of wastage, and lower adverse environmental impacts. This indicates that the IBAssessor ANP model provides a quite logical comparison result for the aim of a sense of emotional and physical well-being of people and lifespan energy efficiency of IBs and thus can be applied in practice.

\section{Conclusions and recommendations}

This paper presents an ANP model, named as IBAssessor, for IB assessments emphasizing the lifespan energy efficiency of buildings. The IBAssessor ANP model is developed based on the ANP containing feedback and self-loops among clusters and subclusters (refer to Fig. 3), but without the control model to simplify the ANP model. KPIs for the IBAssessor model are selected by a quantitative approach called energy-time consumption index (ETI) based on a Strategic Intelligent Building Evaluation and Renovation (SIBER) model (refer 
to Fig. 1) and a Tactical Intelligent Building Evaluation and Renovation (TIBER) model (refer to Fig. 2). However, there are implicit control criteria with respect to which all pairwise judgments are made in this model, i.e. lifespan energy efficiency of buildings focusing on products and processes with respect to the well-being of people. The supermatrix computations are conducted for the overall priorities of IB Candidates, and the priorities are obtained by synthesizing the priorities of the Candidates from all the subnetworks of the IBAssessor ANP model. Finally, the synthesized priority weight Wi is used to distinguish the degree of lifespan energy efficiency due to the deployment of design and construction plans from each IB Candidate. The authors believe that the IBAssessor approach has advantages over the current building rating methods such as the Asian IB index because it can tackle both values and interrelationships among KPIs, which the current building rating systems do not achieve.

In summary, in order to apply the IBAssessor ANP model into practice, this paper recommends the following steps:

1. assess IB Candidates on all KPIs using Table 8 and the scoring criteria of IB Index by the AIIB [5,22];

2. make pairwise comparisons among all indicators usingTables 7 and 9;

3. calculate supermatrix calculation to transform an initial supermatrix to a limiting supermatrix;

4. calculate each limiting priority weight of IB Candidates using limiting supermatrix;

5. select IB Candidate using Table 11.

6. If none of the candidates meets lifespan energy efficiency and well-being requirements, adjust the plans and reevaluate by repeating the above procedure.

Although the IBAssessor ANP model has been built based on a group of KPIs extracted from IB Index, the authors admit that the KPIs adopted in current IBAssessor model are not perfect to provide a complete coverage to lifespan energy efficiency of products and processes as well as well-being of people. Further research needs to go through all current building rating systems and conduct more surveys with practitioners to collect a conclusive group of KPIs to develop a revised IBAssessor model.

\section{Acknowledgements}

The authors of this paper gratefully acknowledge the financial support from the UK government Engineering and Physical Sciences Research Council (EPSRC) Sustainable Urban Environment (SUE) programme under grant number GR/T04878/01. The title of the research project under EPSRC SUE programme is Innovation in Design, Construction and Operation of Buildings for People (IDCOP), partners include ARUP, Imperial College of Science, Technology \& Medicine, the University of Greenwich, the University of Southampton, and the University of Reading.

The authors would also like to acknowledge Louis Landre from the U.S. Army Corps of Engineers (USACE), Xavier Menage' from the Buildings \& Government Efficiency Team of Australian Government Department of the Environment \& Heritage (DEH) for providing valuable reference information. 
Appendix A. Equations

The following equations are used in this paper:

$$
\begin{aligned}
& \mathrm{IBI}=\prod_{i=1}^{9} M_{i}^{w_{i} / \sum_{i=1}^{9} w_{i}} \\
& M_{i}=\prod_{j=1}^{m} x_{j}^{w_{x_{j}} / \sum_{j=1}^{m} w_{x_{j}}} \\
& \mathrm{IBI}=x^{\left.w_{x} /\left(w_{x}+w_{y}\right)\right)^{w_{y}} /\left(w_{x}+w_{y}\right)} \\
& F_{\mathrm{ETI}}=f(e, t) \\
& \mathrm{ETI}_{i}=\frac{\partial F_{\mathrm{ETI}}}{\partial t} \\
& \mathrm{ETI}_{i}=\frac{\sum_{j=1}^{2} \mathrm{SEC}_{i, j}}{\sum_{j=1}^{2} \operatorname{STC}_{i, j}} \\
& \left.w_{i}\right|_{t, J}=\frac{\sum_{i=1}^{l}\left(\alpha_{i j} / \sum_{j=1}^{J} \alpha_{i j}\right)}{J} \\
& W_{i}=\frac{w_{\mathrm{CB}_{\mathrm{B}}, i}}{w_{\mathrm{C}_{\mathrm{BB}}}}=\frac{w_{\mathrm{C}_{\mathrm{IB}}, i}}{\sum_{i} w_{\mathrm{C}_{\mathrm{IB}}, i}}
\end{aligned}
$$




\section{References}

[1] ABCB, Building Code of Australia, Australian Building Codes Board (ABCB), Australia, 2005.

[2] ABS, Overall Liking Score (OLS), ABS Consultanting, London, 2004. http://www.absconsulting.uk.com/ols.htm, 31 May 2005.

[3] H. Adeli, K. Sarma, Life-Cycle Cost Optimization of Structures: Fuzzy Logic, Genetic Algorithm, and Parallel Computing, John Wiley \& Sons, New York, 2005.

[4] D. Adler, Metric Handbook: Planning and Design Data, Elsevier Architectural Press, Oxford, UK, 1999.

[5] AIIB, IB Index, third ed., Asian Institute of Intelligent Buildings (AIIB), Hong Kong, 2005.

[6] T. Alhazmi, R. McCaffer, Project procurement system selection model, ASCE Journal of Construction Engineering and Management 126 (3) (2000) 176-184.

[7] A. Amato, A Comparative Environmental Appraisal of Alternative Framing Systems for Offices, Ph.D. thesis, Oxford Brookes University, UK, 1996.

[8] J. Anderson, K. Mills, Refurbishment or Redevelopment of Office Buildings? Sustainability Comparisons, Building Research Establishment Ltd. (BRE), Garston, UK, 2002, http://www.brebookshop.com/ details.jsp?id=139909, http://www.officescorer.info, 31 May 2005.

[9] J. Anderson, D.E. Shiers, M. Sinclair, The Green Guide to Specification: An Environmental Profiling System for Building Materials and Components, 3rd ed., Blackwell Science Publishing, Oxford, UK, 2002.

[10] K.J. Arrow, H.B. Chenery, B.S. Minhas, R.M. Solow, Capital-labor substitution and economic efficiency, The Review of Economics and Statistics 43 (3) (1961) 225-250.

[11] A.S. Bahaj, D.J. Clements-Croome, D.M. Gann, K. Jones, S.B. Riffat, Suatainable Urban Environment Innovation in Design, Construction and Operation of Buildings for People (IDCOP) - Case for Support to the EPSRC, IDCOP Consortium, UK, 2002.

[12] R. Bassi, MATOOL: a matrix tool for assessing the performance of intelligent buildings, in: Proceedings of the BRE Seminar on Intelligent Buildings, Building Research Establishment Ltd., UK, 2005.

[13] B. Berge, The Ecology of Building Materials, Architectural Press, Oxford, UK, 2000.

[14] D.T. Bickley, Probability distribution of maximum sustained load, ASCE Journal of the Structural Division 100 (11) (1974) 2361-2365.

[15] S. Blanchard, P. Reppe, Life Cycle Analysis of A Residential Home in Michigan, Report No. 1998-5, Master Project, School of Natural Resources and Environment, University of Michigan, USA, 1998, http://alcor.concordia.ca/rvraojw/crd/reference/reference001522.html, 31 May 2005.

[16] S. Blanchard, P. Reppe, Life Cycle Analysis of a Residential Home in Michigan, M.Sc. thesis, University of Michigan, USA, 1998.

[17] D.C. Brown, M.J. Ashleigh, M.J. Riley, R.D. Shaw, New project pro- curement process, ASCE Journal of Management in Engineering 17 (4) (2001) 192-201.

[18] CABA, Building IQ Rating Criteria. Task Force 1-Intelligent Building Ranking System, Continental Automated Building Association (CABA), Ottawa, Canada, 2004.

[19] A. Campagno, Intelligent Glass Facades: Material, Practice, Design, Birkhauser Verlag, AG, Switzerland, 1995.

[20] Z. Chen, H. Li, C.T.C. Wong, Environmental management of urban construction projects in China, ASCE Journal of Construction Engineer- ing and Management 126 (4) (2000) 320-324.

[21] Z. Chen, An Integrated Analytical Approach to Environmental Manage- ment in Construction. ProQuest, USA. UMI Number: AAT 3107430, 2004, http://wwwlib.umi.com/dissertations/preview/3107430, 20 October 2005.

[22] L. Chow, K.L. Cheung, The Intelligent Building Index (IBI) Manual. 10. Health \& sanitation: version 3.0, Asian Institute of Intelligent Buildings, Hong Kong, 2004.

[23] D.K.H. Chua, D. Li, Key factors in bid reasoning model, ASCE Journal of Construction Engineering and Management 126 (5) (2000) 349-357.

[24] D.J. Clements-Croome, Intelligent Buildings: Design, Management and Operation, Thomas Telford, 
London, 2004.

[25] D.J. Clements-Croome, K.G. Jones, G. John, Through life environmental business modelling for sustainable architecture, CIBSE Proceedings of Conference on Building Sustainability, Value and Profit, Edinburgh, UK, 2003.

[26] CMIT, CSIRO Sustainable Built Environment Online Brochures: Embo- died Energy, CSIRO Manufacturing \& Infrastructure Technology (CMIT), Commonwealth Scientific and Industrial Research Organisation (CSIRO), Australia, 2002, http://www.cmit.csiro.au/brochures/tech/ embodied, 31 May 2005.

[27] C.W. Cobb, P.H. Doughlas, A theory of production, American Economic Review 28 (1928) 139-165.

[28] R.J. Cole, Energy and greenhouse gas emissions associated with the construction of alternative structural systems, Building and Environment 34 (3) (1999) 335-348.

[29] CSI, An Overview of The United States National CAD Standard, The Construction Specifications Institute (CSI), USA, 1997, http://www. nationalcadstandard.org/NCSpres2.pdf, 31 May 2005.

[30] I. Dickie, N. Howard, Assessing Environmental Impacts of Construc- tion-Industry Consensus, BREEAM and UK Ecopoints, BRE, UK, 2000. [31] R. Drogemuller, LICHEE: Life Cycle House Energy Estimator, CSIRO Manufacturing and Infrastructure Technology, Australia, 2004, http:// www.cmit.csiro.au/brochures/tech/lichee, 31 May 2005.

[32] K. Eaton, A. Amato, A Comparative Environmental Life Cycle Assess- ment of Modern Office Buildings, Steel Construction Institute, Ascot, UK, 1998.

[33] FIDIC, Guidelines for Business Integrity Management in the Consulting Industry (Test Edition, 2001), International Federation of Consulting Engineers (FIDIC), Switzerland, 2001.

[34] R. Flanagan, G. Norman, Life Cycle Costing for Construction, Royal Institution of Chartered Surveyors, London, UK, 1983.

[35] R. Flanagan, G. Norman, J. Meadows, G. Robinson, Life Cycle Costing: Theory and Practice, Basil Blackwell Scientific Publishing, Oxford, UK, 1989.

[36] D. Hampton, Procurement issues, ASCE Journal of Management in Engineering 10 (6) (1994) 45-49.

[37] D.F. Heathfield, S. Wibe, An Introduction to Cost and Production Functions, Macmillan Education, London, 1986.

[38] C. Hendrickson, A. Horvath, Resource use and environmental emissions of U.S. construction sectors, ASCE Journal of Construction Engineering and Management 126 (1) (2000) 38-44.

[39] IBSK, Assessment Standards for Certifying Intelligent Buildings 2002, Intelligent Building Society of Korea (IBSK), Seoul, Korea, 2002.

[40] S. Islam, Effect of an essential input on isoquants and substitution elasticities, Energy Economics 7 (3) (1985) 194-196.

[41] ISO, ISO 9000:1994-Quality Management and Quality Assurance Standards, International Organization for Standardization (ISO), Swit- zerland, 1993.

[42] ISO, ISO 14040:1997-Environmental Management-Life Cycle Assessment - Principles and framework, International Organization for Standardization (ISO), Switzerland, 2003.

[43] ISO, ISO 9000:2000 - Quality Management Systems - Fundamentals and Vocabulary, International Organization for Standardization (ISO), Switzerland, 2004.

[44] W.T. Hetherington, Canadian Automated Building Protocol (CAB Pro- tocol ${ }^{\mathrm{TM}}$ ) Main Document Version 01-Release 2.0-2.01, Public Works and Government Services Canada, Canada, 1997, http://tech-env.com/ cab.html, 31 May 2005.

[45] A. Jablonski, R. Klempous, B. Licznerski, Diversified approach to methodology and technology in distributed intelligent building systems, in: R. Moreno-D'1az, F. Pichler, Computer Aided Systems Theory (Revised Selected Papers of EUROCAST 2003, Nineth International Workshop on Computer Aided Systems Theory Las Palmas de Gran Canaria, Spain, 24-28 February 2003), Lecture Notes in Computer Science, Springer-Verlag GmbH, Berlin, Germany, 2004.

[46] M. Jakob, R. Madlener, Riding down the experience curve for energy- efficient building envelopes: the Swiss case for, 2020, International Journal of Energy Technology and Policy 2 (1-2) (2004) 153-178.

[47] J.E. Rowings Jr., R.O. Walker Jr., Construction energy use, ASCE Journal of Construction Engineering and Management 110 (4) (1984) 
$447-458$.

[48] M. Kagioglou, R. Cooper, G. Aouad, J. Hinks, M. Sexton, D.M. Sheath, A Generic Guide to the Design and Construction Process Protocol, University of Salford, Salford, UK, 1998.

[49] S.J. Kirk, A.J. Dell'Isola, Life Cycle Costing for Design Professionals, McGrew-Hill Book Company, New York, 1995.

[50] S. Kotaji, A. Schuurmans, S. Edwards, Life-Cycle Assessment in Building and Construction: A State-OfThe-Art Report of Setac Europe, Society of Environmental Toxicology and Chemistry, Brussels, Belgium, 2003.

[51] R. Kumar, S.N. Garg, S.C. Kaushik, Performance evaluation of multi- passive solar applications of a non air-conditioned building, International Journal of Environmental Technology and Management 5 (1) (2005) 60-

75.

[52] B. Li, Assessing the influence of indoor environment on productivity in offices, Ph.D. thesis, University of Reading, UK, 1998.

[53] H. Li, Z. Chen, C.T.C. Wong, P.E.D. Love, A quantitative approach to construction pollution control based on resource levelling, Construction Innovation 2 (2) (2002) 71-81.

[54] W. Lo, C.H. Chao, A. Hadavi, R.J. Krizek, Contractor selection process for Taipei mass rapid transit system, ASCE Journal of Management in Engineering 14 (3) (1998) 57-65.

[55] J. Myerson, Workplace Design, Design Council, London, 2005, http:// www.designcouncil.org.uk/webdav/servlet/XRM?Page/@id=6047\&

Session/@id=D_142wd0mH2OzKacvlm2kD\&Document\%5B@id\% 3D1640\%5D/Chapter/@id=2, 31 May 2005.

[56] NAHB, The Quiet Revolution. National Association of Home Builders (NAHB), Washington, USA, 2002, http://www.nahb.org/publication_details.aspx?sectionID=222\&publicationID=17, 31 May 2005.

[57] NAHB, Life Cycle Assessment Tools to Measure Environmental Impacts: Assessing Their Applicability to the Home Building Industry, Prepared for: U.S. Department of Housing and Urban Development. NAHB Research Center, Inc., Upper Marlboro, USA, 2001, http://www. toolbase.org/tertiaryT.asp?TrackID=\&CategoryID=1\&DocumentID= 4305, 31 May 2005.

[58] NHER, Home Energy Rating: Introduction, National Home Energy Rat- ings (NHER), The National Energy Centre, Milton Keynes, UK, 2004, http://www.nher.co.uk/home-energy-rating-intro.shtml, 31 May 2005.

[59] ODPM (1987), The Town and Country Planning (Use Classes) Order 1987. Office of the Deputy Prime Minister (ODPM), UK, http://www.

odpm.gov.uk/stellent/groups/odpm_planning/documents/downloadable/ odpm_plan_033434.pdf, 31 May 2005.

[60] T. Oka, M. Suzuki, T. Konnya, The estimation of energy consumption and amount of pollutants due to the construction of buildings, Energy and Buildings 19 (1993) 303-311.

[61] P.G.T. Owens, Intelligent skings for buildings, ASHRAE Transactions 96 (1) (1990) 3-8.

[62] E. Palaneeswaran, M.M. Kumaraswamy, Contractor selection for design/ build projects, ASCE Journal of Construction Engineering and Manage- ment 126 (5) (2000) 331-339.

[63] PMI, A Guide to the Project Management Body of Knowledge (PMBOK Guide), third ed., Project Management Institute, USA, 2004.

[64] Profiles, New YorkCity Building Classification Codes, Profiles Publica- tions, Inc., New York, USA, 2004,http://www.nyforeclosures.com/cgibin/SoftCart.exe/articles/biccodes.htm?L+scstore+vwgx5689ffb2aeb2+ 1113088040, 31 May 2005.

[65] X. Qi, Effective utility function and its criterion, in: Proceedings of the Second China Economics Annual $\begin{array}{llll}\text { Conference, } & \text { Northwest University, }\end{array}$ http://www.cenet.org.cn/cn/ReadNews.asp?NewsID=6035, 31 May 2005.

[66] S. Raymond, R. Cunliffe, Tomorrow's Office: Creating Effective and Humane Interiors, E\&FN Spon, London, UK, 1997.

[67] S. Roaf, Adapting Buildings and Cities for Climate Change: A 21st Century Survival Guide, Architectural Press, Oxford, UK, 2005. 
[68] S. Roaf, A. Horsley, R. Gupta, Closing the Loop: Benchmarks for Suatainable Buildings, RIBA Enterprises Ltd., London, UK, 2004.

[69] S. Roaf, M. Hancock, Energy Efficient Building: A Design Guide, Blackwell Scientific, Oxford, UK, 1992.

[70] T.L. Saaty, Decision-making with the AHP: why is the principal eigen- vector necessary, in: Proceedings of ISAHP 2001, Berne, Switzerland, 2001.

[71] T.L. Saaty, Fundamentals of the ANP, in: ISAHP Proceedings, Kobe, Japan, 1999.

[72] T.L. Saaty, Decision Making with Dependence and Feedback: The Analytic Network Process, RWS Publications, Pittsburgh, USA, 1996.

[73] S. Sayce, A. Walker, A. McIntosh, Building Sustainability in the Balance: Promoting Stakeholder Dialogue, Estates Gazette, UK, 2004.

[74] SCC, Shanghai Intelligent Building Appraisal Specification, Shanghai Construction Council (SCC), Shanghai, China, 2002.

[75] J. Seddon, The Case Against ISO 9000, second ed., Cork, Ireland, 2001. [76] SEDO, Introduction to House Energy Principles, Sustainable Energy Development Office (SEDO), Government of Western Australia, Aus- tralia, 2004, http://www1.sedo.energy.wa.gov.au/pages/her_intro.asp\#2, 31 May 2005.

[77] SEEDA, Sustainability Checklist, the South East Development Agency (SEEDA), Guildford, UK, 2004, http://www.sustainability-checklist. co.uk/index.html, 31 May 2005. [78] D.K. Smith, Total Life-cycle Cost Model (Presentation), Facility Infor- mation Council, National Institute of Building Sciences, USA, 2000, http://nibs.org/TLCM/TotalLifeCycle2000B.pdf, 31 May 2005.

[79] E. Teicholz, Facility Design and Management Handbook, McGraw-Hill, New York, USA, 2001.

[80] G. Treloar, R. Fay, S. Tucker, in: Proceedings of the embodied energy: the current state of play Seminar, The School of Architecture \& Building, Deakin University, Australia, 1998.

[81] G. Treloar, R. Fay, P.E.D. Love, U. Iyer-Raniga, Analysing the life-cycle energy of an Australian residential building and its householders, Building Research \& Information 28 (3) (2000) 184-195.

[82] H. Tufty, Value engineering made mandatory on EPA projects over

$\$ 10,000,000$, Civil Engineering, ASCE 46 (9) (1976) 101-103.

[83] USACE, Engineering and Design—Life Cycle Design and Performance, ER 1110-2-8159, CECW-ED, The U.S. Army Corps of Engineers (USACE), USA, 1997.

[84] USACE, A Guide for Project Partners - Life Cycle of a Civil Works Project, The U.S. Army Corps of Engineers (USACE), USA, 2000, http:// www.nwp.usace.army.mil/re/LifeCycle.htm, 31 May 2005.

[85] USACE, Sustainable Project Rating Tool (SPiRiT) (Version 1.4.1), The

U.S. Army Corps of Engineers (USACE), USA, 2001, http://www.cecer. army.mil/SustDesign/SPiRiT.cfm, 31 May 2005.

[86] USACE, Management-U.S. Army Corps of Engineers Business Pro- cess, Publication Number: ER 51-11, The U.S. Army Corps of Engi- neers (USACE), Washington, USA, 2001, http://www.usace.army.mil/ inet/usace-docs/eng-regs/er5-1-11/entire.pdf, 31 May 2005.

[87] USACE, Programs Management (CECW-B), Directorate of Civil Works, the U.S. Army Corps of Engineers (USACE), Washington, USA, 2001, http://www.usace.army.mil/inet/functions/cw/cecwb, 31

May 2005.

[88] USACE, Facility Composer: a life-cycle facility model based on industry standards, the U.S. Army $\begin{array}{lllll}\text { Corps of Engineers } & \text { (USACE), Washington, }\end{array}$ http://www.erdc.usace.army.mil/pls/erdcpub/www_welcome.

navigation_page?tmp_next_page=46970, 31 May 2005.

[89] USGBC, LEED: Leadership in Energy and Environmental Design, the

U.S. Green Building Council (USGBC), Washington, USA, 2005, http:// www.usgbc.org, 31 May 2005.

[90] USGSA, The Integrated Workplace: A Comprehensive Approach to Developing Workspace, Office of Real Property, the Office of Govern- mentwide Policy, the U.S. General Services Administration (USGSA), Washington, USA, 1999, http://www.gsa.gov/gsa/cm_attachments/GSA_ DOCUMENT/integrated_workplace_rpt_pdf_R2OD26_0Z5RDZ-i34K-pR.pdf, 31 May 2005.

[91] USNIBS, Excellence in Facilities Management: Five Federal Case Studies, The U.S. National Institute 
of Building Sciences (USNIBS), Washington, USA, 1998, http://nibs.org/casestdy.pdf, 31 May 2005.

[92] USNIBS, Facility performance evaluation (FPE), National Institute of Building Sciences (USNIBS), Washington, USA, 2005, http://www. wbdg.org/design/fpe.php, 31 May 2005.

[93] M. Wigginton, J. Harris, Intelligent Skins, Elsevier Architectural Press, London, 2002.

[94] K.C. Wong, A. So, N. Yu, The financial viability of intelligent buildings: a Faustmann approach of assessment, Journal of Financial Management of Property and Construction 6 (1) (2001) 41-50.

[95] K.C. Wong, T.P. So, Y.T. Leung, The Intelligent Building Index (IBI) Manual: Version 2.0, Asian Institute of Intelligent Buildings, Hong Kong, 2001.

[96] J.K.W. Wong, H. Li, S.W. Wang, Intelligent building research: a review, Automation in Construction 14 (1) (2005) 143-159.

[97] X. Yin, A tractable alternative to Cobb-Douglas utility for imperfect competition, Australian Economic Papers 40 (1) (2001) 14-21.

[98] J.L. Zachariah, C. Kennedy, K. Pressnail, What makes a building green? International Journal of Environmental Technology and Management 2 (1-3) (2002) 38-53.

[99] JSBC, Comprehensive Assessment System for Building Environmental Efficiency (CASBEE), Japan Sustainable Building Consortium (JSBC), Institute for Built Environment and Energy Conservation (IBEC), Tokyo, Japan, 2004.

[100] R.J. Cole, Review of GBTool and Analysis of GBC 2002 Case-Study Projects, International Initiative for a Sustainable Built Environment (IISBE), Canada, 2002, http://greenbuilding.ca/iisbe/gbc2k2/GBC_ 2002_Analysis.pdf, 31 May 2005.

[101] HK-BEAM Society, Hong Kong Building Environmental Assessment Method, HK-BEAM Society, Hong Kong, 2004.

[102] DEH, National Australian Built Environment Rating System, Depart- ment of the Environment and Heritage (DEH), Australia, 2004.

[103] Arup, SPeAR ${ }^{1}$ : Product overview, Arup, London, 2002, http://www. arup.com/environment/feature.cfm?pageid=1685, 31 May 2005.

[104] GMB, Green Mark for Builfings, Building and Construction Authority, Singapore, http://www.bca/gov.sg, 31 May 2005.

[105] A. Amato, L. Brimacombe, N. Howard, Development of quantitative methodology for assessing embodied energy of recyclable and reusable materials/products, Ironmaking and Steelmaking 23 (3) (1996) 235-241.

[106] P. Mikula, The Definitive Guide to Forecasting Using W.D. Gann's Square of Nine, Mikula Forecasting Company, 2003.

[107] T. Stephens, Impact of earlier global warming long-lasting: new findings show a slow recovery from extreme global warming episode 55 million years ago, Currents Online, UC Santa Cruz, 2005, http://currents.ucsc. edu/04-05/06-13/ocean.asp, 16 June 2005. \#

[108] P.B. Meyer, Econterms, EconPort (A microeconomics digital library), http://www.econport.org:8080/econport/request?page=web_glossary\& glossaryLetter=C, 16 June 2005.

[109] E.E. Vargas, D.F. Schreiner, G. Tembo, D.W. Marcouiller, Computable General Equilibrium Modeling for Regional Analysis, Regional Research Institute, West Virginia University, USA, http://www.rri.wvu. edu/WebBook/Schreiner/contents.htm, 16 June 2005.

[110] BRE, Embodied Energy of Building Materials. Building Research Establishment Ltd., UK, 1994, http://www.ecosite.co.uk/depart/backinfo/ bldmat.htm, 16 June 2005.

[111] Ricoh, Pursuing the Ideal Society. Ricoh Co., Ltd., 2005, http://www. ricoh.com/environment/management/earth.html, 16 June 2005.

[112] A.R. Schotter, Microeconomics:, A Modern Approach, 3/E, Addison- Wesley, Boston, USA, 2001.

[113] M.J. Osborne, Tutorial on the theory of the firm and industry equilibrium, on-line tutorials, Department of Economics of the University of Toronto, Toronto, Canada, 1997, http://www.chass.utoronto.ca/rvosborne, 6 October 2005.

[114] S.L. Wen, Manual of Intelligent Building Assessment, Architecture and Building Research Institute, Ministry of the Interior, Taiwan, China, ISBN: 957016137X, 2003. 
